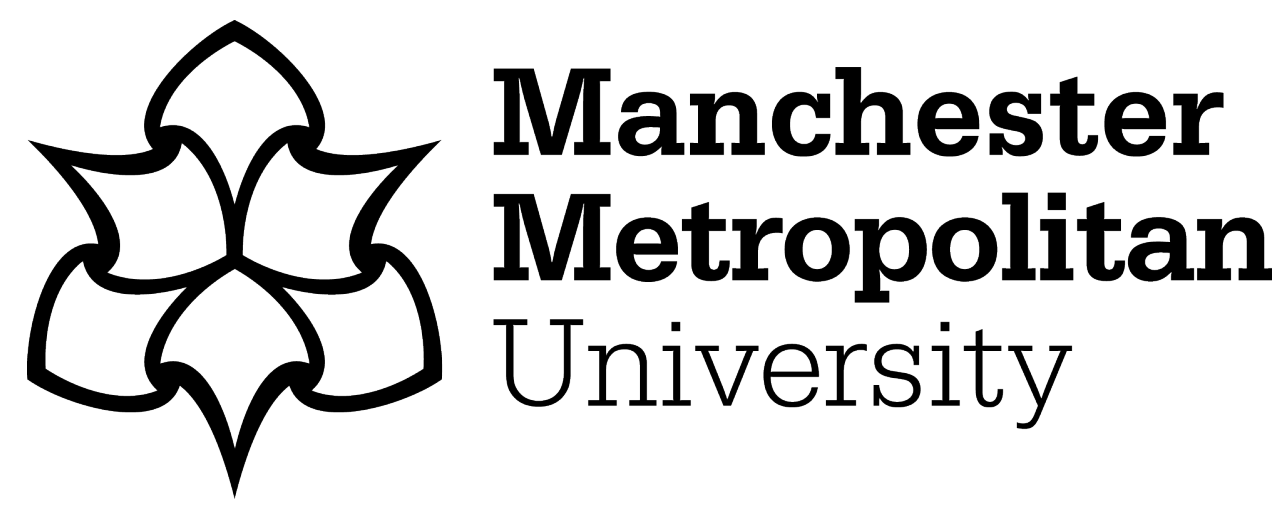

Zahnow, Renee, McVeigh, Jim ORCID logoORCID: https://orcid.org/00000001-5319-6885, Bates, Geoff and Winstock, Adam R (2020) Motives and Correlates of Anabolic-Androgenic Steroid Use With Stimulant Polypharmacy. Contemporary Drug Problems, 47 (2). pp. 118-135. ISSN 0091-4509

Downloaded from: https://e-space.mmu.ac.uk/625593/

Version: Accepted Version

Publisher: SAGE Publications

DOI: https://doi.org/10.1177/0091450920919456

Please cite the published version 


\title{
Motives and correlates of anabolic-androgenic steroid use with stimulant polypharmacy
}

\begin{abstract}
Individuals who use anabolic-androgenic steroids (AAS) may engage in concurrent psychoactive drug use recreationally and/or as an additional training aid. Aside from cannabis, individuals who use AAS most commonly report concurrent use of stimulants such as amphetamines and cocaine. In this study we examine demographic characteristics, frequency of heavy drinking and night-clubbing in a sample of 993 men from the Global Drug Survey (GDS) 2015 who reported both AAS and psychoactive drug use before exploring the relationship between motivation for AAS use and the propensity to concurrently engage with stimulant type substances. Results of a logistic regression analysis suggest that the propensity for concurrent use of AAS and stimulants is greater when AAS use is motivated by weight loss goals while performance goals are associated with reduced odds of concurrent stimulant use. Identifying individuals who are at risk of poly-drug use and associated harms can inform targeted harm reduction strategies.
\end{abstract}

KEY WORDS: psychoactive drugs; anabolic steroids; poly-drug; stimulants 


\section{Motivations for anabolic steroid use associated with the co-use of illicit stimulants}

The harm associated with the use of illicit substances is a global health concern (Degenhardt, Hall, \& Stone, 2016; Larance, Degenhardt, Copeland, \& Dillon, 2008; Parkinson \& Evans, 2006; Sagoe, Molde, Andreaseen, Torsheim \& PAllesen, 2014; Sagoe \& Pallesen, 2018). While rates of use and drugs of choice vary significantly across international contexts, the growing knowledge of and accessibility to, a diverse range of substances particularly via the internet is ubiquitous (Chandler \& McVeigh, 2014; Griffiths \& Mounteney, 2017; Hope et al., 2013). Poly-drug use - the concurrent use of multiple substances - is well documented in studies of individuals who use illicit drugs and is associated with increased risks of adverse health effects (Molero, Bakshi, \& Gripenberg, 2017) and can complicate medical responses in the case of an emergency event (Nieschlag \& Vorona, 2015).

Poly-drug use is a common feature of image and performance enhancement drug (IPED) protocols (Dodge \& Hoagland, 2011; Hildebrandt, Langenbucher, Carr, \& Sanjuan, 2007; Ip et al., 2015; Korkia \& Stimson, 1993; Lenehan, Bellis, \& McVeigh, 1996; McBride, Williamson, \& Petersen, 1996; Sagoe et al., 2015). Most of the research in this area focuses on poly-drug use as related to the practice of "stacking". Stacking refers to the use of multiple types of steroids and other IPEDs to enhance performance, muscle building and fat loss, or to counter unwanted effects of AAS (Hoffman \& Ratamess, 2006). However, there is also research with samples of bodybuilders, gym attendees and drug rehabilitation participants that suggests polysubstance use can extend beyond typical image and performance enhancing drugs to include illicit, psychoactive substances (Hope et al., 2013; Molero et al., 2017; Sagoe et al., 2015). Psychoactive substances may be taken to enhance the fat burning effects of AAS, aid sleep and recovery or manage pain (Ip et al., 2017; Molero et al., 2017; Sagoe et al., 2015). For example, stimulants such as amphetamines and cocaine can increase energy 
allowing one to train harder while also incurring fat burning benefits (Nilsson, Baigi, Marklund, \& Fridlund, 2001; Sagoe et al., 2015).

There is also evidence that individuals who use steroids may engage in psychoactive drug use recreationally (Dodge \& Hoagland, 2011; Hope et al., 2013; Ip et al., 2017; Molero et al., 2017; Sagoe et al., 2015; Salasuo \& Piispa, 2012). Indeed, a study conducted on a large sample of gym attendees in Sweden found that AAS use was associated with lifetime history of psychoactive drug use and that previous psychoactive drug use separated AAS users from nonusers who had been offered AAS but declined (Hakansson, Mickelsson, Wallin, \& Berglund, 2012). Another study reports that aside from cannabis, the three most commonly used psychoactive substances among gym attendees in Sweden are cocaine, amphetamine and ecstasy; approximately $40 \%$ of those who used drugs reported poly-drug use (Molero et al., 2017). Individuals who had used illicit psychoactive substances were three times more likely to report use of AAS than gym attendees who had never used illicit, stimulant drugs.

Using multiple substances simultaneously can increase the risk of negative impacts associated with any one of the drugs being ingested (Baggio, Studer, Mohler-Kuo, Daeppen, \& Gmel, 2014; Connor, Gullo, White, \& Kelly, 2014; Linn \& Line, 2018). Here, we focus on the concurrent use of AAS and stimulants, specifically amphetamines and cocaine, (as opposed to opiates, hypnotics or illicitly used pharmaceuticals) for two key reasons: first, stimulants are the most frequently used psychoactive drug type among individuals who use steroids (aside from cannabis) and use can be related to training goals or recreational pursuits (Molero et al., 2017; Sagoe et al., 2015; Skarberg, Nyberg, \& Engstrom, 2009), and second, research demonstrates that when used concurrently, AAS and stimulants work synergistically to exacerbate the cardiotoxic, and potentially the neurological, effect of either drug taken in isolation (Welder \& Melchert, 1993). 


\section{Concurrent use of stimulants and steroids}

Adverse health outcomes associated with the chronic use of AAS are well documented. AAS use has been linked to acne, depression, hypogonadism, testicular atrophy and gynecomastia (Nieschlag \& Vorona, 2015; Zahnow, McVeigh, Ferris, \& Winstock, 2017). The use of AAS can also have deleterious effects on the cardiovascular system leading to myocardial infarction, changes in cardiac structure and function, elevated blood lipid levels and hypertension (Angell et al., 2012; Baggish et al., 2017; Di Paolo et al., 2007; Fisher, Appleby, Rittoo, \& Cotter, 1996; Günep, Erbap, Okuyan, Babalýk, \& Gürmen, 2004; Liu \& Wu, 2019; Montisci et al., 2012; Nieminen et al., 1996; Pereira dos Santos, Coutinho de Oliveira, \& Silva, 2014; Santamarina, Besocke, Romano, Ioli, \& Gonorazky, 2008; Thiblin, Lindquist, \& Rajs, 2000). Most recently, scholars have found evidence that steroid use can lead to declines in cognitive functioning and changes in brain anatomy (Bjørnebekk et al., 2017; Kanayama, Kean, Hudson, \& Pope, 2013; Westlye, Kaufmann, Alnæs, Hullstein, \& Bjørnebekk, 2017). Structural brain imaging reveals long-term exposure to AAS is associated with smaller overall brain volume and thinner cortex; effects that may underlie the noted correlation between AAS exposure and a range of psychiatric symptoms and cognitive deficits (Bjørnebekk et al., 2017).

The cardiotoxic effects of stimulants are remarkably similar to those of AAS. The use of stimulants can lead to hypertension, acute and chronic heart failure, myocardial infarction, and increased heart rate (Ghuran \& Nolan, 2000). Among otherwise low risk adults, the risk of acute myocardial infarction is 24 times greater in the first hour following cocaine consumption (Mittleman et al., 1999). Engaging in intense exercise and/ or the concurrent use of AAS alongside cocaine use serves to further exacerbate the risk myocardial events (Lange \& Hillis, 2001; Welder \& Melchert, 1993). Individuals who use AAS and cocaine, and also engage in intensive exercise, are at greatest risk of myocardial events because these drugs 
work synergistically to enhance the drugs' negative effects on the cardiovascular system (Welder \& Melchert, 1993). Like AAS use, chronic stimulant exposure is also linked to a number of psychiatric symptoms and neural anatomical adaptations that can persist beyond cessation of substance use (Substance Abuse and Mental Health Services Administration, 1999).

Another factor that increases risk when using both AAS and stimulants is that steroids can slow and diminish the stimulant effects experienced by the user. This can lead to the user taking larger doses of the stimulant to gain the desired effect. Studies reveal the modulating effect of AAS on the psychoactive properties of stimulants such as cocaine and ecstasy (Kurling, Kankaanpää, \& Seppälä, 2008; Lindqvist, Johansson-Steensland, Nyberg, \& Fahlke, 2002; Phillis, Irvine, \& Kennedy, 2000; Tseng, Rockhold, Hoskins, \& Ho, 1994). Specifically, pre-treatment with AAS is associated with a decrease in the activation of the brain's reward system and diminishes the effects of cocaine and ecstasy (Kurling et al., 2008; Lindqvist et al., 2002). AAS induced changes in the effects of stimulants may lead to reliance on larger doses to achieve the desired outcomes which, in turn, can lead to higher risk of overdose and dependence. While the studies reported here were carried out on animals and cannot be replicated on human samples, case studies support these findings. Psychostimulant use was detected in 23 of a total 24 cases of unexplained death involving AAS in NSW, Australia between 1995-2012 (Darke, Torok, \& Duflou, 2014). Extensive cardiovascular disease was evident in all 24 cases despite a relatively low mean age of just 31.7 years. The study concluded that given the widespread use of psychostimulants in this group it was likely that the "combination of AAS and psychostimulants increases the risk of cardiovascular disease" (Darke et al., 2014). p.1028). A case study involving the sudden unexpected death of a female athlete similarly reported the concurrent use of AAS and ephedrine was the key factor causing death (Klötz, Petersson, Hoffman, \& Thiblin, 2010). Another study associated 
heart failure in a male athlete with past consumption of AAS, cocaine and amphetamines (Martinez-Quintana et al., 2013).

A complicating factor when considering concurrent AAS and stimulant use is that the context in which non-training related stimulant use occurs may differ considerably from that of AAS use. The use of AAS is generally goal driven, planned and involves prolonged use. The benefits of AAS accumulate over time; they do not induce an immediate bodily sensation (e.g. feelings of euphoria). In contrast, the recreational use of stimulants tends to occur in social settings and may be opportunistic, impulsive and sporadic (Hildebrandt, 2015). The effects of stimulants are felt immediately; stimulants release large quantities of dopamine into the brain inducing a sense of euphoria (dela Peña, Gevorkiana, \& Shi, 2015). Given the differences in both the social setting and normative patterns of AAS and recreational stimulant use, individuals may not recognise the two as inter-related or consciously acknowledge the potential for drug interaction. This aspect of the drug use again increases the risk of short and long term consequences by reducing an individual's awareness of the potential for cross-drug interactions.

Studies on specific samples of male steroid users including homosexual men (Ip et al., 2017), recreational gym-goers (Hakansson et al., 2012; Molero et al., 2017) and bodybuilders (Sagoe et al., 2015) have demonstrated that concurrent AAS and stimulant use occurs within these population groups. Additionally, a number of studies have identified individual level factors associated with this type of poly-drug use. One study, conducted by Petersson, Bengtsson, Voltaire-Carlsson, and Thiblin (2010) examined motivations for AAS use in a sample of 20 men attending an addiction clinic for dependence related to another psychoactive substance (alcohol, opiates, pharmaceuticals, other illicit drugs). Among these men, the most commonly reported motivation for AAS use was a desire to attain a nice body. Other motivating factors included: to become stronger; curiosity; because others were using, 
and; to perform better in sport (Petersson et al., 2010). Skarberg, Nyberg and Engstrom's (2011) study of 32 poly-drug users attending an addiction clinic revealed similar results. The men's AAS use was motivated by muscle and strength gains while the use of amphetamine was driven by endurance and fat loss goals.

Individuals who use steroids have reported using stimulants both recreationally and for sports performance enhancement (Angoorani, Narenjiha, Tayyebi, Ghassabian, Ahmadi, \& Assari, 2009). Individual characteristics related to substance use broadly, including poor knowledge of associated risks, impulsivity and a proclivity for risk-taking may also be associated with problematic use of AAS and/or stimulant drugs (Kanayama et al, 2010; Miller et al., 2005). While research in this area is developing, currently, few studies elucidate factors associated with AAS related poly-drug use in non-clinical, non-athlete samples. A better understanding of motivations for AAS use in the context of also using stimulants may help to identify individuals at risk of this type of poly-drug use and, in turn, facilitate the design of targeted harm minimization strategies.

\section{The Current Study}

In the current study we explore patterns of poly-drug use in a sample of men who report lifetime use of AAS and a subset of the sample who report use of AAS in the last 12 months. After establishing the relative frequency of co-occurring stimulant use compared to other drug types, in this sample of men of use AAS, we assess whether or not stated motivation for AAS use is associated with the propensity for individuals to also engage in stimulant use. This is important as there may be significant differences in motivations for AAS and stimulant use in samples used in previous research who were recruited from clinics, gyms and bodybuilding circles, compared to individuals primarily recruited as self-identified, recreational, psychoactive drug users. The way this group utilise stimulants may be 
particularly problematic for thinking about interactions between AAS and stimulants; this group may also have higher levels of lifestyle risk. A better understanding of the characteristics associated with concurrent AAS and stimulant use can inform more effective harm minimization strategies and help to identify individuals most at risk of engaging in this form of poly-substance use. It is particularly important to explore this issue outside the sporting and bodybuilding population given that evidence demonstrates that steroids are utilized by a broad range of individuals in the general population for aesthetic purposes.

\section{Study Methods}

\section{Study Design and Sample}

The Global Drug Survey (GDS) is an online, anonymous survey designed to capture in-depth information about the use of alcohol, tobacco and illicit substances. Since its inception in 2009, the GDS has been conducted annually. Here we use data from the GDS 2015, which was collected between November 2014 and January 2015. A total of 89509 responses were completed during this time. The GDS survey is self-completed on a selfnominating basis; in 2015, it was promoted in partnership with a range of media including national newspapers, magazines, web sites and social media outlets (Global Drug Survey, 2015) and was available in 11 languages (English, German, Greek, Polish, French, Italian, Spanish, Portuguese, Flemish, Hungarian and Danish). Other publications provide details on the design, utility and limitations of the GDS (Barratt, Ferris, \& Winstock, 2014; Global Drug Survey, 2015; Winstock, Lynskey, Borschmann, \& Waldron, 2015). The GDS 2015 was approved by the Kings College Research Ethics Committee (PNM/14/15-18 Global Drug Survey). All participants provided written informed consent. 
In this study we are interested in a sub-sample of the GDS; males who reported using injectable or oral anabolic steroids. A total of 993 (1.1\%) men reported lifetime use of AAS, of these, $287(0.3 \%)$ men reported using AAS in the last 12 months (see Table 1).

\section{Measures}

The GDS asks respondents to report on their use of more than 100 substances, including but not limited to, alcohol, tobacco, cannabis, amphetamines, cocaine, opiates, novel psychoactive substances, solvents and anabolic steroids. In the initial stages of the survey respondents are presented with a drug screen. For each substance, respondents are asked to report whether they have ever used; aged first used; when last used and frequency of use.

Details of steroid use: Respondents who reported lifetime use of AAS in the drug screen are directed to a section of the GDS on performance enhancers. In this section of the survey respondents are asked to report on their lifetime and last year use of a range of performance enhancing drugs including AAS. To measure motivations for using these drugs, respondents are asked to rate on a scale ranging from (1) not important at all to (4) very important, how important are the following four goals: building muscle; weight loss; improving performance; improving my self-esteem/confidence.

Details of stimulant use: Using the initial drug screen responses, we created a dichotomous variable to indicate respondents' recent stimulant use. Respondents who reported they had used any form of amphetamine, methamphetamine, cocaine, crack cocaine, or novel psychoactive substances in the last 12 months were given a 1 on this variable. Respondents who did not report recent use of any of these substances were assigned a 0 .

Details of other drug use: Using the same process as outlined above, the initial drug screen responses were coded to compile a dichotomous indicator of recent depressant use and recent 
use of hallucinogens. Respondents who reported they had used any form of cannabis; opioids; benzodiazepine (not prescribed to them); opium; GHB; GBL; methadone; nitrous or butane in the last 12 months were given a 1 on the depressant indicator variable and those who did not use any of the listed substances in the last 12 months were assigned a 0 on this variable. Respondents who reported they had used magic mushrooms; ketamine; LSD; PCP; DMT; peyote or mescaline in the last 12 months were given a 1 on the hallucinogen indicator and those who did not use these substances in the last 12 months were assigned a 0 .

Demographics characteristics, frequency of heavy drinking and night-clubbing: The GDS asks respondents to report their gender, age, sexual orientation, country of residence, employment status and highest level of education. In addition, the GDS collects information about aspects of respondents' lifestyle. We use two items measuring, frequency of heavy drinking (eight drinks or more in a single session) and frequency of clubbing, to capture lifestyle risk. These behaviours may be associated with stimulant use (Leslie et al., 2015; Van Havere, Vanderplasschen, Lammertyn, Broekaert, \& Bellis, 2011). Respondents are asked to report how often they have more than 8 drinks on one occasion: never; less than monthly; monthly; weekly; daily. For the purposes of the analyses the weekly and daily categories were aggregated. Respondents are also asked to report how often they go clubbing: never; less than once every three months; once every three months; once a month; once a fortnight; once or twice per week; three to four times per week; more than four times per week. For the purposes of the analyses the final three categories were aggregated to indicate clubbing frequency of weekly or more.

\section{Statistical Analyses}

The analyses proceed in two stages. First, we explore patterns of AAS and other substance use within the GDS sample using descriptive statistics. Second, we employ logistic 
regression analysis to examine whether the odds of a recent AAS user concurrently using stimulants is associated with demographic characteristics, frequency of heavy drinking and night-clubbing or particular motivations for using AAS. The dependent variable in the logistic regression is a dichotomous variable indicating recent use of both AAS and stimulants $(0=$ no; $1=y e s)$. The key independent variables measure the importance of four potential motivations for AAS use, to: gain muscle; lose weight; improve performance; increase self-esteem. Frequency of heavy drinking and night-clubbing are included to capture lifestyle factors associated with stimulant use. Demographic characteristics including age, region of residence, education and employment are included in the logistic regression as control variables. All independent variables are outlined in the variable descriptions above. Data were processed and analysed using Stata 14.0 (StataCorp, 2015).

\section{Results}

\section{Descriptive statistics}

The GDS sample comprised a total of 57, 484 men who had never used AAS; 993 men who reported lifetime use of AAS and 287 men who reported using AAS in the last 12 months (see Table 1). The most commonly used substance among all participants, including recent AAS users, was cannabis (see Table 2). After excluding cannabis from the depressant category (as cannabis is not illicit in all regions surveyed), the use of stimulant drugs in the last 12 months is the most common type of poly-drug use reported by recent AAS users. $59.9 \%$ of recent AAS report also using stimulants in the last 12 months; $32.4 \%$ reporting using depressants (not including cannabis) and 51.6\% reporting using hallucinogens in the last 12 months. Among individuals who recently used AAS, $41.8 \%$ also used ecstasy in the last 12 months; $38.7 \%$ used cocaine in the last 12 months and $20.6 \%$ used amphetamine in the last 12 months. 
The final analytic cohort for the logistic regression comprised 215 men who reported using AAS in the last 12 months and also provided responses to the item related to motivations for AAS use. The average age of the analytic sample was 29.5 years $(\mathrm{SD}=10.4)$. The majority were employed (71.2\%) and had engaged in post-school education $(75.9 \%)$. A total of $143(66.5 \%)$ respondents reported using stimulants in the last 12 months.

The results of the logistic regression analysis demonstrate that the odds of an individual who uses AAS to also use stimulants in the last 12 months is significantly higher among individuals who report that losing weight is quite important (OR=4.94, 95\% CI: 1.6614.66, $\mathrm{p}<0.001)$ or very important $(\mathrm{OR}=3.71,95 \% \mathrm{CI}: 1.70-12.84, \mathrm{p}<0.05)$ when compared to individuals who report that losing weight is not important. of the likelihood of an individual who uses AAS to also use stimulants in the last 12 months is moderately higher among individuals who report that building muscle is very important $(\mathrm{OR}=6.25,95 \% \mathrm{CI}$ : 1.28 $30.46, \mathrm{p}<0.05)$ and is moderately lower among individuals who report that performance goals are very important $(\mathrm{OR}=0.30,95 \% \mathrm{CI}$ : $0.08-1.07)$ compared to those who report that building muscle and performance are not important, respectively. While p values suggest these associations are statistically significant, post-hoc Wald tests demonstrate moderate associations only (muscle building: $\chi^{2}=0.57$, ns; performance: $\chi^{2}=0.09$, ns). Frequency of heavy alcohol use is also associated with the propensity for AAS users to simultaneously engage in stimulant use; individuals who engage in heavy drinking weekly or more are more likely than those who do not engage in frequent heavy drinking to use both AAS and stimulants (OR=13.45, 95\% CI: 3.14-57.55, $\mathrm{p}<0.001)$. Similarly, individuals who engage in frequent nightclubbing are more likely than those who do not go nightclubbing to report poly- 
drug use involving AAS and stimulants in the last 12 months. There was no significant effect of age, employment or education on the propensity for recent AAS users to also report using stimulants in the last 12 months. Results of the logistic regression model are presented in Table 4.

\section{Discussion}

The primary aim of this study was to explore poly-drug in a sample of men who use AAS and examine whether particular motivations for using AAS were associated with the concurrent use of illicit stimulants among the sample. Compared to AAS users who did not use stimulants, individuals who use AAS for aesthetic purposes, such as weight loss, are more likely to report concurrent use of AAS and stimulants than those who are not motivated by weight loss goals. Additionally, heavy drinking and night-clubbing at a higher frequencies was more common among individuals reporting concurrent use of stimulants and AAS than their non-stimulant using counterparts. Together, these findings suggest that in our sample those at greatest risk of engaging in concurrent use of stimulants and AAS are non-athletes concerned with the body enhancement benefits of anabolic steroids. Scholars have referred to this group as 'aesthetes' (Petersson et al., 2010) and the YOLO type (You Only Live Once) (Christiansen, Vinther, \& Liokaftos, 2016; Zahnow et al., 2018). This group of AAS users are described as individuals who seek to improve their appearance and, in turn, self-confidence by enhancing muscularity and leanness through the use of steroids (Petersson et al., 2010).

In this study, we focused on the concurrent use of AAS and stimulants for two reasons: first, because stimulants are the most frequently used psychoactive drug type among individuals who use steroids (with the exception of cannabis). Second, there are significant health risks associated with using both AAS and stimulants yet there is limited awareness of the synergistic properties of stimulants and AAS among users and service providers. Of 
particular concern is the harm associated with using cocaine and alcohol while also on a cycle of AAS which can result in the formation of the toxic Cocaethylene (Dasgupta, 2017). In this study, with the exception of cannabis, stimulants were the most frequently used drug type among those who recently used AAS. Within the stimulant category, ecstasy was used most frequently by individuals who also used AAS, followed by cocaine and amphetamine. The results of this study provide support for previous research conducted with small samples of individuals who use AAS drawn from clinical populations (Kanayama, Cohane, Weiss \& Pope, 2003; Skarberg, Nyberg \& Engstrom, 2009) or with AAS using gym attendees/fitness participants (Kanayama, Pope, Cohane \& Hudson, 2003; Ip, Barnett, Tenerowicz \& Perry 2011) where participants have reported using stimulants as training aids and/or recreationally. Our findings also align with those of research focussed on youth populations that indicates individuals who experiment with illicit drugs are more likely to use many drug types, including AAS and stimulants (Miller et al, 2005; Pallesen, Josendal, Johnsen, Larsen \& Molde, 2006).

Our study demonstrates that education on the additional implications of using AAS alongside stimulants should be provided to health care and drug service workers as well as substance users and potential users. Given the group of individuals engaging in this type of poly-drug use also report high levels of heavy drinking it is also important to highlight the impact of adding alcohol to the mix of AAS and stimulants. Concurrent use of AAS, stimulants and alcohol may significantly increase the risk of dehydration and related health concerns such as cardiac distress (Althobaiti \& Sari, 2016; Miller, Barnes, Sabo, Melnick, \& Farrell, 2002; Onakomaiya \& Henderson, 2016). Interviews with individuals who use AAS have demonstrated that use of steroids is associated with greater propensity to experience negative consequences of alcohol use (Meilman, Crace, Presley, \& Lyerla, 1995) and 
drinking alcohol while AAS is also present in the body may increase the effects of alcohol on self-control and aggression (Meilman et al., 1995).

Given the enhanced health risks associated with the concurrent use of AAS and stimulants and that effective approaches to preventing uptake and encouraging cessation of substance use are embedded in a comprehensive understanding of motivating factors and the benefits individuals derive from use, in this study we focused on identifying motivating factors for AAS use in this high risk group of users. Beyond achieving this primary aim, the study findings lead to an important observation; they highlight a group of males who engage in high risk, poly-drug use associated with unique health implications that go beyond those of individual substances. Also concerning is that risky, polysubstance use tends to co-occur with other high risk behaviours including heavy drinking, unprotected sex (Downing et al., 2011; Kokkevi et al., 2014) and violence (Steele \& Peralta, 2017)

Stigma and perceived stigma are barriers to engagement of both psychoactive drug users (Lloyd, 2013) and AAS users (Zahnow et al., 2017) in primary care, and there is no reason to believe that concomitant behaviours would serve to overcome this barrier. Given the complex chemical interactions between stimulants and AAS coupled with the large range of potential, acute and chronic adverse effects, it is clear that populations engaging in this form of poly-substance use would benefit from early interventions to reduce harms and monitor health. Given these individuals' propensity to engage in a number of risky lifestyle behaviours combined with an apparent resistance to primary health care services, needle and syringe programs or steroid related services may offer a unique opportunity for meaningful, holistic health care interventions with this hard to reach, vulnerable population group. Providing educational materials at these services on the effects of drug interactions may be avenue for harm reduction. 


\section{Limitations}

We acknowledge that this study has a number of limitations. Firstly, the sample of individuals who report recent use of both AAS and stimulants is relatively small and it is restricted to self-identified, psychoactive drug users. Given the sampling method is selfselection, the findings may not generalise to the broader AAS or stimulant using populations. Second, in reporting motivations for AAS use participants were limited to six options specified in the survey instrument ${ }^{1}$. We recognise that these do not cover the full spectrum of motivations that may drive AAS use. The survey also did not collect information on whether stimulant use was motivated by training goals or recreation. Given that individuals who reported concurrent use of stimulants and AAS in this sample also frequently engaged in heavy drinking, combined with the fact that the sample is a group of self-identified psychoactive substance users we suggest the majority of stimulant use is recreational. Finally, we recognise that while the clinical utility of the findings is limited, it is important to identify that a minority of AAS using individuals who are engaged in risky lifestyle behaviours such as heavy drinking and night-clubbing and/or are motivated to use AAS by weight loss goals may be at increased risk of adverse effects and require targeted approaches to reduce harms.

\section{Conclusions}

Overall, the findings presented here continue to highlight the need to move away from targeting all steroid prevention efforts at athletes and instead move toward prevention, education and health promotion strategies that target the general population. Incorporating steroids into existing drug education programs in schools and providing information to facilitate risk reduction at environments where stimulant use is more likely to occur such as music events and in night-time entertainment areas, alongside information on other types of

\footnotetext{
${ }^{1}$ Four are reported in our study there were too few responses to each of the other two motivations to enable their inclusion in the logistic analysis.
} 
recreational drugs, is a relatively low cost, harm reduction strategy that is easy to implement. Further, drug services such as needle and syringe programs and steroid outreach services have great potential to serve as avenues for delivering holistic health care and early intervention to prevent risky lifestyle activities to a high risk, health service resistant population group; currently this is an opportunity missed. The findings reported here demonstrate the importance of continually reviewing and renewing approaches to delivering safety messaging around drug use and moving away from the male athlete assumption in regards to steroid use (Miller et al., 2002). 


\section{References}

Althobaiti, Y. S., \& Sari, Y. (2016). Alcohol interactions with psychostimulants: an overview of animal and human studies. Journal of addiction research \& therapy, 7(3).

Angell, P., Chester, N., Green, D., Somauroo, J., Whyte, G., \& George, K. (2012). Anabolic Steroids and Cardiovascular Risk. Sports Medicine, 42(2), 119-134. doi:10.2165/11598060-000000000-00000

Baggio, S., Studer, J., Mohler-Kuo, M., Daeppen, J.-B., \& Gmel, G. (2014). Concurrent and simultaneous polydrug use among young Swiss males: use patterns and associations of number of substances used with health issues International Journal of Adolescent Medicine and Health (Vol. 26, pp. 217).

Baggish, A. L., Weiner, R. B., Kanayama, G., Hudson, J. I., Lu, M. T., Hoffmann, U., \& Pope, H. G. (2017). Cardiovascular Toxicity of Illicit Anabolic-Androgenic Steroid Use. Circulation, 135(21), 1991-2002. doi:10.1161/circulationaha.116.026945

Barratt, M., Ferris, J., \& Winstock, A. (2014). Use of Silk Road, the online drug marketplace, in the UK, Australia and the USA. Addiction, 109(5), 774-783. doi:10.1111/add.12470

Bates, G., \& McVeigh, J. (2016). Image and Performance Enhancing Drugs- 2015 Survey Results. Retrieved from Liverpool: http://www.cph.org.uk/wpcontent/uploads/2016/07/IPEDs-2015-survey_final1.pdf

Bjørnebekk, A., Walhovd, K. B., Jørstad, M. L., Due-Tønnessen, P., Hullstein, I. R., \& Fjell, A. M. (2017). Structural Brain Imaging of Long-Term Anabolic-Androgenic Steroid Users and Nonusing Weightlifters. Biological Psychiatry, 82(4), 294-302. doi:https://doi.org/10.1016/j.biopsych.2016.06.017

Chandler, M., \& McVeigh, J. (2014). Steroids and image enhancing drugs 2013 survey results. Liverpool: LJMU Centre for Public Health. 
Christiansen, A. V., Vinther, A. S., \& Liokaftos, D. (2016). Outline of a typology of men's use of anabolic androgenic steroids in fitness and strength training environments. Drugs: education, prevention and policy, 1-11. doi:10.1080/09687637.2016.1231173

Cohen, J., Collins, R., Darkes, J., \& Gwartney, D. (2007). A league of their own: demographics, motivations and patterns of use of 1,955 male adult non-medical anabolic steroid users in the United States. Journal of the International Society of Sports Nutrition, 4(1), 12. doi:10.1186/1550-2783-4-12

Connor, J. P., Gullo, M. J., White, A., \& Kelly, A. B. (2014). Polysubstance use: diagnostic challenges, patterns of use and health. Current Opinion in Psychiatry, 27(4), 269-275. doi:10.1097/yco.0000000000000069

Darke, S., Torok, M., \& Duflou, J. (2014). Sudden or unnatural deaths involving anabolicandrogenic steroids. Journal of Forensic Sciences, 59. doi:10.1111/1556-4029.12424

Dasgupta, A. (2017). Combined alcohol and drug abuse: a potentially deadly mix. In A. Dasgupta (Ed.), Alcohol, Drugs, Genes and the Clinical Laboratory: Elsevier.

Degenhardt, L., Hall, W., \& Stone, C. (2016). Illicit drugs: Patterns of use, dependence, and contribution to disease burden in developed countries. In K. J. Sher (Ed.), The Oxford Handbook of Substance Use and Substance Use Disorders Two-Volume Set (pp. 5066). New York, USA: Oxford University Press.

dela Peña, I., Gevorkiana, R., \& Shi, W.-X. (2015). Psychostimulants affect dopamine transmission through both dopamine transporter-dependent and independent mechanisms. European Journal of Pharmacology, 764, 562-570. doi:10.1016/j.ejphar.2015.07.044

Di Paolo, M., Agozzino, M., Toni, C., Luciani, A. B., Molendini, L., Scaglione, M., .. . Arbustini, E. (2007). Sudden anabolic steroid abuse-related death in athletes. 
International Journal of Cardiology, 114(1), 114-117.

doi:https://doi.org/10.1016/j.ijcard.2005.11.033

Dodge, T., \& Hoagland, M. F. (2011). The use of anabolic androgenic steroids and polypharmacy: a review of the literature. Drug Alcohol Depend, 114.

Downing, J., Hughes, K., Bellis, M. A., Calafat, A., Juan, M., \& Blay, N. (2011). Factors associated with risky sexual behaviour: a comparison of British, Spanish and German holidaymakers to the Balearics. European Journal of Public Health, 21(3), 275-281. doi:10.1093/eurpub/ckq021

Fisher, M., Appleby, M., Rittoo, D., \& Cotter, L. (1996). Myocardial infarction with extensive intracoronary thrombus induced by anabolic steroids. British Journal of Clinical Practice, 50(4), 222-223.

Ghuran, A., \& Nolan, J. (2000). Recreational drug misuse: issues for the cardiologist. Heart, 83(6), 627-633. doi:10.1136/heart.83.6.627

Global Drug Survey. (2015). Global Drug Survey: The GDS sample. Retrieved from https://www.globaldrugsurvey.com/gds-surveys/gds-sample-and-characteristics/

Griffiths, P., \& Mounteney, J. (2017). Disruptive potential of the internet to transform illicit drug markets and impact on future patterns of drug consumption. Clinical Pharmacology \& Therapeutics, 101(2), 176-178.

Günep, Y., Erbap, C., Okuyan, E., Babalýk, E., \& Gürmen, T. (2004). Myocardial infarction with intracoronary thrombus induced by anabolic steroids. Anatol J Cardiol, 4(4), 357-358. doi:doi:

Hakansson, A., Mickelsson, K., Wallin, C., \& Berglund, M. (2012). Anabolic androgenic steroids in the general population: User characteristics and associations with substance use. European Addiction Research, 18(2), 83-90. doi:10.1159/000333037 
Hildebrandt, T. (2015). Gateways to Appearance and Performance Enhancing Drug Use. Paper presented at the Nordic Conference on Appearance and Performance Enhancing Drugs \& Anti-Doping Work, Helinski.

\section{https://dopinglinkki.fi/sites/default/files/attachment/aped2015_hildebrandt_1.pdf}

Hildebrandt, T., Langenbucher, J. W., Carr, S. J., \& Sanjuan, P. (2007). Modeling population heterogeneity in appearance- and performance-enhancing drug (APED) use: Applications of mixture modeling in 400 regular APED users.

Export EXPORT Add To My List Email Print Share. Journal of Abnormal Psychology, 116(4), 717-733.

Hoffman, J. R., \& Ratamess, N. A. (2006). Medical issues associated with anabolic steroid use: are they exaggerated? Journal of sports science \& medicine, 5(2), 182.

Hope, V. D., McVeigh, J., Marongiu, A., Evans-Brown, M., Smith, J., Kimergård, A., . . . Ncube, F. (2013). Prevalence of, and risk factors for, HIV, hepatitis B and C infections among men who inject image and performance enhancing drugs: a crosssectional study. BMJ Open, 3(9).

Ip, E. J., Barnett, M. J., Tenerowicz, M. J., \& Perry, P. J. (2011). The Anabolic 500 survey: Characteristics of male users versus nonusers of anabolic-androgenic steroids for strength training. Pharmacotherapy: The journal of human pharmacology and drug therapy, 31(8), 757-766.

Ip, E. J., Trinh, K., Tenerowicz, M. J., Pal, J., Lindfelt, T. A., \& Perry, P. J. (2015). Characteristics and Behaviors of Older Male Anabolic Steroid Users. Journal of Pharmacy Practice, 28(5), 450-456. doi:10.1177/0897190014527319

Ip, E. J., Yadao, M. A., Shah, B. M., Doroudgar, S., Perry, P. J., Tenerowicz, M. J., . . Pope, H. G. (2017). Polypharmacy, Infectious Diseases, Sexual Behavior, and Psychophysical Health Among Anabolic Steroid-Using Homosexual and 
Heterosexual Gym Patrons in San Francisco's Castro District. Substance Use \& Misuse, 52(7), 959-968. doi:10.1080/10826084.2016.1267224

Iversen, J., Topp, L., Wand, H., \& Maher, L. (2013). Are people who inject performance and image-enhancing drugs an increasing population of Needle and Syringe Program attendees? Drug and Alcohol Review, 32(2), 205-207. doi:10.1111/j.14653362.2012.00499.x

Kanayama, G., Brower, K., Wood, R., Hudson, J. \& Pope, H. (2010) Treatment of anabolicandrogenic steroid dependence: Emerging evidence and its implications. Drugs and Alcohol Dependence, 1(3), 6-13. doi.org/10.1016/j.drugalcdep.2010.01.011

Kanayama, G, Cohane, G, Weiss, R, \& Pope, H. (2003) Past anabolic-androgenic steroid use among men admitted for substance abuse treatment: an underrecognized problem? The Journal of Clinical Psychiatry;64(2):156-160. DOI: 10.4088/jcp.v64n0208.

Kanayama, G., Kean, J., Hudson, J. I., \& Pope, H. G. (2013). Cognitive deficits in long-term anabolic-androgenic steroid users. Drug and Alcohol Dependence, 130(1), 208-214. doi:https://doi.org/10.1016/j.drugalcdep.2012.11.008

Kanayama, G., Pope Jr., H., Cohane, G. \& Hudson, J. (2003). Risk factors for anabolicandrogenic steroid use among weightlifters: a case-control study. Drug \& Alcohol Dependance. $71,77-86$.

Klötz, F., Petersson, A., Hoffman, O., \& Thiblin, I. (2010). The significance of anabolic androgenic steroids in a Swedish prison population. Compr Psychiatry, 51. doi:10.1016/j.comppsych.2009.05.007

Kokkevi, A., Kanavou, E., Richardson, C., Fotiou, A., Papadopoulou, S., Monshouwer, K., . . Olszewski, D. (2014). Polydrug use by European adolescents in the context of other problem behaviours. Nordic Studies on Alcohol and Drugs, 31(4), 323-342. doi:10.2478/nsad-2014-0026 
Korkia, P., \& Stimson, G. (1993). Anabolic steroid use in Great Britain: an exploratory investigation. Final report to the Department of Health for England, Scotland and Wales. London: The Centre for Research on Drugs and Health Behaviour.

Kurling, S., Kankaanpää, A., \& Seppälä, T. (2008). Sub-chronic nandrolone treatment modifies neurochemical and behavioral effects of amphetamine and 3,4methylenedioxymethamphetamine (MDMA) in rats. Behavioural Brain Research, 189(1), 191-201. doi:https://doi.org/10.1016/j.bbr.2007.12.021

Lange, R. A., \& Hillis, L. D. (2001). Cardiovascular Complications of Cocaine Use. New England Journal of Medicine, 345(5), 351-358. doi:10.1056/nejm200108023450507

Larance, B., Degenhardt, L., Copeland, J., \& Dillon, P. (2008). Injecting risk behaviour and related harm among men who use performance-and image-enhancing drugs. Drug Alcohol Rev, 27. doi:10.1080/09595230802392568

Lenehan, P., Bellis, M., \& McVeigh, J. (1996). A study of anabolic steroid use in the North West of England. J Perform Enhanc Drugs, 1 .

Leslie, E. M., Smirnov, A., Cherney, A., Wells, H., Kemp, R., Legosz, M., \& Najman, J. M. (2015). Engagement with different nightlife venues and frequent ecstasy use in a young adult population. Drugs: education, prevention and policy, 22(4), 380-384.

Lindqvist, A.-S., Johansson-Steensland, P., Nyberg, F., \& Fahlke, C. (2002). Anabolic androgenic steroid affects competitive behaviour, behavioural response to ethanol and brain serotonin levels. Behavioural Brain Research, 133(1), 21-29. doi:https://doi.org/10.1016/S0166-4328(01)00408-9

Linn, G., \& Line, B. J. A. (2018). Patterns of substance use and mortality risk in a cohort of ‘hard-to-reach' polysubstance users. Addiction, 113(4), 729-739. doi:doi:10.1111/add.14053 
Liu, J. \& Wu, Y. (2019) Anabolic-androgenic steroid and cardiovascular risk. Chinese Medical Journal, 132(18), 2229-2236.

Lloyd, C. (2013). The stigmatization of problem drug users: A narrative literature review. Drugs: education, prevention and policy, 20(2), 85-95. doi:10.3109/09687637.2012.743506

Martinez-Quintana, E., Saiz-Udaeta, B., Marrero-Negrin, N., Lopez-Mérida, X., RodriguezGonzalez, F., \& Nieto-Lago, V. (2013). Androgenic Anabolic Steroid, Cocaine and Amphetamine Abuse and Adverse Cardiovascular Effects. International Journal of Endocrinology and Metabolism, 11(4), e8755. doi:10.5812/ijem.8755

McBride, A. J., Williamson, K., \& Petersen, T. (1996). Three cases of nalbuphine hydrochloride dependence associated with anabolic steroid use. Br J Sports Med, 30. doi:10.1136/bjsm.30.1.69

Meilman, P. W., Crace, R. K., Presley, C. A., \& Lyerla, R. (1995). Beyond performance enhancement: polypharmacy among collegiate users of steroids. Journal of American College Health, 44(3), 98-104.

Miller, K. E., Barnes, G. M., Sabo, D. F., Melnick, M. J., \& Farrell, M. P. (2002). AnabolicAndrogenic Steroid Use and Other Adolescent Problem Behaviors: Rethinking the Male Athlete Assumption. Sociological Perspectives, 45(4), 467-489. doi:10.1525/sop.2002.45.4.467

Miller, K.E., Hoffman, J.H., Barnes, G.M., Sabo, D., Melnick, M.J.\& Farrell, M.P.,(2005). Adolescent anabolic steroid use, gender, physical activity, and other problem behaviors. Substance Use and Misuse 40, 1637-1657.

Mittleman, M. A., Mintzer, D., Maclure, M., Tofler, G. H., Sherwood, J. B., \& Muller, J. E. (1999). Triggering of Myocardial Infarction by Cocaine. Circulation, 99(21), 27372741. doi:10.1161/01.cir.99.21.2737 
Molero, Y., Bakshi, A.-S., \& Gripenberg, J. (2017). Illicit Drug Use Among Gym-Goers: a Cross-sectional Study of Gym-Goers in Sweden. Sports Medicine - Open, 3, 31. doi:10.1186/s40798-017-0098-8

Montisci, M., El Mazloum, R., Cecchetto, G., Terranova, C., Ferrara, S. D., Thiene, G., \& Basso, C. (2012). Anabolic androgenic steroids abuse and cardiac death in athletes: Morphological and toxicological findings in four fatal cases. Forensic Science International, 217(1), e13-e18. doi:https://doi.org/10.1016/j.forsciint.2011.10.032

Nieminen, M. S., Ramo, M. P., Vitasalo, M., Heikkila, P., Karjalainen, J., Mantysaari, M., \& Heikkila, J. (1996). Serious cardiovascular side effects of large doses of anabolic steroids in weight lifters. European Heart Journal, 17(10), 1576-1583.

Nieschlag, E., \& Vorona, E. (2015). Doping with anabolic androgenic steroids (AAS): Adverse effects on non-reproductive organs and functions. Reviews in Endocrine and Metabolic Disorders, 16(3), 199-211. doi:10.1007/s11154-015-9320-5

Nilsson, S., Baigi, A., Marklund, B., \& Fridlund, B. (2001). The prevalence of the use of androgenic anabolic steroids by adolescents in a county of Sweden. European Journal of Public Health, 11(2), 195-197. doi:10.1093/eurpub/11.2.195

Onakomaiya, M. M., \& Henderson, L. P. (2016). Mad men, women and steroid cocktails: a review of the impact of sex and other factors on anabolic androgenic steroids effects on affective behaviors. Psychopharmacology, 233(4), 549-569. doi:10.1007/s00213$015-4193-6$

Parkinson, A. B., \& Evans, N. A. (2006). Anabolic androgenic steroids: A survey of 500 users. Med Sci Sports Exerc, 38(4), 644-651.

Pallesen, S., Jøsendal, O., Johnsen, B., Larsen, S. \& Molde, H. (2006). Anabolic steroid use in high school students. Substance Use \& Misuse 41, 1705-1717. 
Pereira dos Santos, M. A., Coutinho de Oliveira, C. V., \& Silva, A. S. (2014). Adverse Cardiovascular Effects from the Use of Anabolic-Androgenic Steroids as Ergogenic Resources. Substance Use \& Misuse, 49(9), 1132-1137. doi:10.3109/10826084.2014.903751

Petersson, A., Bengtsson, J., Voltaire-Carlsson, A., \& Thiblin, I. (2010). Substance abusers' motives for using anabolic androgenic steroids. Drug and Alcohol Dependence, 111(1), 170-172. doi:http://dx.doi.org/10.1016/j.drugalcdep.2010.04.008

Phillis, B. D., Irvine, R. J., \& Kennedy, J. A. (2000). Combined cardiac effects of cocaine and the anabolic steroid, nandrolone, in the rat. European Journal of Pharmacology, 398(2), 263-272. doi:https://doi.org/10.1016/S0014-2999(00)00294-6

Sagoe, D., Molde, H., Andreassen, C. S., Torsheim, T., \& Pallesen, S. (2014). The global epidemiology of anabolic-androgenic steroid use: A meta-analysis and metaregression analysis. Annals of Epidemiology, 24, 383-398.Sagoe, D., McVeigh, J., Bjørnebekk, A., Essilfie, M.-S., Andreassen, C. S., \& Pallesen, S. (2015). Polypharmacy among anabolic-androgenic steroid users: A descriptive metasynthesis. Substance Abuse Treatment, Prevention, and Policy, 10(1), 12. doi:10.1186/s13011015-0006-5

Sagoe, D., \& Pallesen, S. (2018). Androgen abuse epidemiology. Current Opinion in Endocrinology, Diabetes, \& Obesity, 25, 185-194.

Salasuo, M., \& Piispa, M. (2012). Perspectives to Doping Substance Use outside Elite Sports in Finland. . Retrieved from Helinski:

Santamarina, R. D., Besocke, A. G., Romano, L. M., Ioli, P. L., \& Gonorazky, S. E. (2008). Ischemic Stroke Related to Anabolic Abuse. Clinical Neuropharmacology, 31(2), 8085. doi:10.1097/WNF.0b013e3180ed4485 
Skarberg, K., Nyberg, F., \& Engstrom, I. (2009). Multisubstance Use as a Feature of Addiction to Anabolic-Androgenic Steroids. European Addiction Research, 15(2), 99106.

StataCorp. (2015). Stata: Release 14. Statistical Software. College Station, Texas: StataCorp LP.

Steele, J. L., \& Peralta, R. L. (2017). Are Polydrug Users More Physically and Verbally Aggressive? An Assessment of Aggression Among Mono- Versus Polydrug Users in a University Sample. Journal of Interpersonal Violence, 0886260517715024. doi:10.1177/0886260517715024

Substance Abuse and Mental Health Services Administration. (1999). Treatment for Stimulant Use Disorders. Treatment Improvement Protocol (TIP) Series. Retrieved from https://www.samhsa.gov/

Thiblin, I., Lindquist, O., \& Rajs, J. (2000). Cause and Manner of Death Among Users of Anabolic Androgenic Steroids. Journal of Forensic Sciences, 45(1), 16-23.

Tseng, Y. T., Rockhold, R. W., Hoskins, B., \& Ho, I. K. (1994). Cardiovascular toxicities of nandrolone and cocaine in spontaneously hypertensive rats. Toxicological Sciences, 22(1), 113-121.

Van Havere, T., Vanderplasschen, W., Lammertyn, J., Broekaert, E., \& Bellis, M. (2011). Drug use and nightlife: more than just dance music. Substance Abuse Treatment, Prevention, and Policy, 6(1), 18.

Welder, A. A., \& Melchert, R. B. (1993). Cardiotoxic effects of cocaine and anabolicandrogenic steroids in the athlete. Journal of Pharmacological and Toxicological Methods, 29(2), 61-68. doi:http://dx.doi.org/10.1016/1056-8719(93)90052-G 
Westlye, L. T., Kaufmann, T., Alnæs, D., Hullstein, I. R., \& Bjørnebekk, A. (2017). Brain connectivity aberrations in anabolic-androgenic steroid users. NeuroImage : Clinical, 13, 62-69. doi:10.1016/j.nicl.2016.11.014

Winstock, Lynskey, M., Borschmann, R., \& Waldron, J. (2015). Risk of emergency medical treatment following consumption of cannabis or synthetic cannabinoids in a large global sample. Journal of Psychopharmacology, 29(6), 698-703. doi:10.1177/0269881115574493

Zahnow, R., McVeigh, J., Bates, G., Hope, V., Kean, J., Campbell, J., \& Smith, J. (2018). Identifying a typology of men who use anabolic androgenic steroids (AAS). International Journal of Drug Policy, 55, 105-112.

Zahnow, R., McVeigh, J., Ferris, J., \& Winstock, A. (2017). Adverse effects, help seeking and ratings of service helpfulness among anabolic androgenic steroid users. Contemporary Drug Problems, 44(1), 69-83. 
Table 1. Demographic characteristics

\begin{tabular}{|c|c|c|c|c|c|c|}
\hline Characteristics & $\begin{array}{l}\text { Never used } \\
(\mathrm{N}=57,484)\end{array}$ & $\begin{array}{c}\text { Never used } \\
(\%)\end{array}$ & $\begin{array}{c}\text { Ever used } \\
(\mathrm{N}=993)\end{array}$ & $\begin{array}{c}\text { Ever used } \\
(\%)\end{array}$ & $\begin{array}{l}\text { Used in the } \\
\text { last } 12 \mathrm{mths} \\
(\mathrm{N}=287)\end{array}$ & $\begin{array}{c}\text { Used in the } \\
\text { last } 12 \mathrm{mths} \\
(\%)\end{array}$ \\
\hline Age mean min-max & 30.17 & $(16-89)$ & 32.03 & $(16-78)$ & 31.05 & $(17-78)$ \\
\hline \multicolumn{7}{|l|}{ Region of residence } \\
\hline Europe & 47,387 & $(81.5)$ & 525 & $(52.9)$ & 148 & $(51.6)$ \\
\hline North America & 3,308 & $(5.2)$ & 104 & $(10.5)$ & 29 & $(10.1)$ \\
\hline South Americas & 3,102 & (5.3) & 243 & $(24.5)$ & 66 & $(23.0)$ \\
\hline Oceania & 4,073 & (7.0) & 104 & $(10.5)$ & 37 & $(12.9)$ \\
\hline Other & 536 & $(0.9)$ & 17 & (1.7) & 7 & (2.4) \\
\hline \multicolumn{7}{|l|}{ Education } \\
\hline School only & 13,603 & $(23.8)$ & 237 & $(24.3)$ & 67 & $(23.8)$ \\
\hline Tafe or certificate & 19,804 & (34.6) & 376 & $(38.5)$ & 118 & $(41.8)$ \\
\hline University & 23,768 & $(41.6)$ & 363 & $(37.2)$ & 97 & $(34.4)$ \\
\hline \multicolumn{7}{|l|}{ Employment } \\
\hline Employed & 35,744 & $(62.1)$ & 708 & $(72.2)$ & 200 & $(70.7)$ \\
\hline Unemployed/student & 21,865 & $(38.0)$ & 272 & $(27.8)$ & 83 & $(29.3)$ \\
\hline \multicolumn{7}{|l|}{ Steroid Use } \\
\hline Age first used & & & 23.37 & (SD 8.95) & 26.17 & (SD 10.63) \\
\hline \multicolumn{7}{|l|}{ Inject steroid } \\
\hline No oral only & & & 453 & $(45.6)$ & 102 & $(35.5)$ \\
\hline Inject & & & 540 & $(54.4)$ & 185 & $(64.5)$ \\
\hline
\end{tabular}

NOTES: Total sample of GDS 2015 respondents was 89,509. Samples included here include only male respondents. 287 individuals reported recent use of AAS but only 215 individuals completed the survey item assessing motivations so the logistic analyses utilises a sample of 215 . Some percentage totals may not equate to 100 due to missing data. 
Table 2. Use of psychoactive drugs and alcohol among males: GDS, lifetime AAS users and recent AAS users

\begin{tabular}{|c|c|c|c|c|c|c|}
\hline & $\begin{array}{c}\text { Never } \\
\text { used } \\
(\mathrm{N}=57484)\end{array}$ & $\begin{array}{c}\text { Never used } \\
(\%)\end{array}$ & $\begin{array}{c}\text { Ever used } \\
(\mathrm{N}=993)\end{array}$ & $\begin{array}{c}\text { Ever used } \\
(\%)\end{array}$ & $\begin{array}{l}\text { Used in the } \\
\text { last } 12 \text { mths } \\
(\mathrm{N}=287)\end{array}$ & $\begin{array}{l}\text { Used in the } \\
\text { last } 12 \mathrm{mths} \\
(\%)\end{array}$ \\
\hline \multicolumn{7}{|l|}{ Frequency of alcohol use } \\
\hline Not in the last $12 \mathrm{mths}$ & 3,240 & (5.7) & 126 & $(13.0)$ & 28 & $(10.0)$ \\
\hline Monthly or less & 7,671 & $(13.5)$ & 178 & $(18.3)$ & 67 & $(23.9)$ \\
\hline 2-4 times a month & 16,286 & $(28.6)$ & 270 & $(27.8)$ & 78 & $(27.9)$ \\
\hline 2-3 times a week & 19,944 & $(35.0)$ & 283 & $(29.1)$ & 80 & $(28.6)$ \\
\hline 4 or more times a week & 9,912 & (17.4) & 116 & (11.9) & 27 & $(9.6)$ \\
\hline \multicolumn{7}{|l|}{$\begin{array}{l}\text { Frequency of heavy drinking ( } 8 \\
\text { drinks or more) }\end{array}$} \\
\hline Never & 8,589 & $(16.0)$ & 110 & $(13.1)$ & 36 & $(14.4)$ \\
\hline Less than monthly & 20,355 & $(38.0)$ & 363 & $(43.4)$ & 111 & $(44.4)$ \\
\hline Monthly & 14,410 & $(26.9)$ & 204 & $(24.4)$ & 48 & $(19.2)$ \\
\hline Weekly & 9,330 & (17.4) & 144 & $(17.2)$ & 51 & $(20.4)$ \\
\hline Daily & 869 & (1.6) & 16 & (1.9) & 4 & (1.6) \\
\hline \multicolumn{7}{|l|}{ Illicit Drug Use } \\
\hline $\begin{array}{l}\text { Min age used any illicit drug } \\
\text { (excl. AAS) }\end{array}$ & 16.64 & (SD 4.62) & 16.94 & (SD 5.22) & 17.25 & (SD 6.25) \\
\hline \multicolumn{7}{|l|}{ Have used a stimulant drug } \\
\hline Ever & 31,419 & $(54.0)$ & 803 & $(80.9)$ & 234 & $(81.5)$ \\
\hline In the last 12 months & 19,300 & $(33.2)$ & 491 & $(49.5)$ & 172 & $(59.9)$ \\
\hline \multicolumn{7}{|l|}{ Have used a depressant drug } \\
\hline Ever & 48,504 & $(83.4)$ & 934 & $(94.1)$ & 266 & $(92.7)$ \\
\hline In the last 12 months & 37,654 & $(64.8)$ & 708 & $(71.3)$ & 216 & $(75.3)$ \\
\hline \multicolumn{7}{|l|}{$\begin{array}{l}\text { Have used a other (incl. } \\
\text { hallucinogens) drug }\end{array}$} \\
\hline Ever & 34,815 & $(59.9)$ & 811 & $(81.7)$ & 227 & $(79.1)$ \\
\hline In the last 12 months & 18,642 & $(32.1)$ & 437 & $(44.1)$ & 148 & $(51.6)$ \\
\hline \multicolumn{7}{|l|}{$\begin{array}{l}\text { Use of drugs in the last } 12 \\
\text { months }\end{array}$} \\
\hline $\begin{array}{l}\text { Have not used any } \\
\text { stimulants/ depressants/ } \\
\text { hallucinogens }\end{array}$ & 16,498 & $(28.4)$ & 169 & $(17.0)$ & 29 & $(10.1)$ \\
\hline Depressants only & 15,642 & $(26.9)$ & 209 & $(21.1)$ & 56 & $(19.5)$ \\
\hline Stimulants only & 954 & (1.6) & 38 & $(3.8)$ & 17 & $(5.9)$ \\
\hline Other only & 2,231 & $(3.8)$ & 34 & (3.4) & 5 & (1.7) \\
\hline Two types & 11,664 & $(20.1)$ & 274 & $(27.6)$ & 82 & $(28.6)$ \\
\hline All three types & 11,147 & $(19.2)$ & 269 & $(27.1)$ & 98 & $(34.2)$ \\
\hline \multicolumn{7}{|l|}{ Specific drug types } \\
\hline \multicolumn{7}{|l|}{ Have used amphetamines } \\
\hline Mean min. age & 20.37 & (SD 5.53) & 21.10 & $(\mathrm{SD} 7.02)$ & 21.09 & $(\mathrm{SD} 7.52)$ \\
\hline Ever & 19,703 & $(33.9)$ & 489 & $(49.3)$ & 141 & $(49.1)$ \\
\hline In the last 12 months & 7,449 & $(12.8)$ & 170 & $(17.1)$ & 59 & $(20.6)$ \\
\hline \multicolumn{7}{|l|}{ Have used cocaine } \\
\hline Mean min.age & 21.85 & $(\mathrm{SD} 5.02)$ & 21.85 & (SD 5.70) & 22.05 & $(\mathrm{SD} 6.30)$ \\
\hline Ever & 19,706 & $(33.9)$ & 620 & $(62.4)$ & 176 & $(61.3)$ \\
\hline In the last 12 months & 10,109 & $(17.4)$ & 305 & $(30.7)$ & 111 & $(38.7)$ \\
\hline \multicolumn{7}{|l|}{ Have used benzodiazepine } \\
\hline Mean min.age & 22.61 & $(\mathrm{SD} 7.41)$ & 23.98 & (SD 7.80) & 24.84 & $(\mathrm{SD} 8.05)$ \\
\hline Ever & 8,380 & $(14.4)$ & 345 & $(34.7)$ & 100 & $(34.8)$ \\
\hline In the last 12 months & 5,131 & $(8.8)$ & 219 & $(22.1)$ & 81 & $(28.2)$ \\
\hline \multicolumn{7}{|l|}{ Have used cannabis } \\
\hline Mean min.age & 17.00 & $(\mathrm{SD} 3.61)$ & 17.58 & (SD 4.76) & 17.49 & (SD 4.59) \\
\hline Ever & 47,824 & $(82.3)$ & 906 & $(91.2)$ & 252 & $(87.8)$ \\
\hline In the last 12 months & 36,108 & $(62.1)$ & 625 & $(62.9)$ & 181 & $(63.1)$ \\
\hline
\end{tabular}


Have used ecstasy

\begin{tabular}{|c|c|c|c|c|c|c|}
\hline Mean min.age & 21.03 & (SD 5.29) & 21.61 & (SD 5.76) & 21.95 & (SD 6.39) \\
\hline Ever & 22,630 & $(38.9)$ & 592 & $(59.6)$ & 176 & (61.3) \\
\hline In the last 12 months & 14,840 & $(25.5)$ & 332 & (33.4) & 120 & $(41.8)$ \\
\hline \multicolumn{7}{|l|}{ Have used LSD } \\
\hline Mean min.age & 20.55 & (SD 4.34) & 21.31 & (SD 5.26) & 21.50 & (SD 5.58) \\
\hline Ever & 14,874 & $(25.6)$ & 452 & $(45.5)$ & 118 & $(41.1)$ \\
\hline In the last 12 months & 6,035 & $(10.4)$ & 177 & $(17.8)$ & 52 & $(18.1)$ \\
\hline \multicolumn{7}{|l|}{ Have used NPS } \\
\hline Mean min.age & 22.31 & (SD 6.37) & 24.87 & $(\mathrm{SD} 8.21)$ & 23.70 & $(\mathrm{SD} 7.70)$ \\
\hline Ever & 9,159 & $(15.7)$ & 283 & $(28.5)$ & 89 & (31.0) \\
\hline In the last 12 months & 4,880 & (8.4) & 114 & (11.5) & 40 & (13.9) \\
\hline \multicolumn{7}{|l|}{ Have used opiates } \\
\hline Mean min.age & 22.48 & $(\mathrm{SD} 7.80)$ & 23.56 & (SD 8.93) & 23.24 & (SD 8.66) \\
\hline Ever & 10,211 & $(17.6)$ & 304 & $(30.6)$ & 85 & $(29.6)$ \\
\hline In the last 12 months & 3,657 & (6.3) & 114 & (11.5) & 44 & $(15.3)$ \\
\hline \multicolumn{7}{|l|}{ Have used Other } \\
\hline Mean min.age & 18.38 & (SD 5.63) & 19.16 & (SD 5.84) & 19.69 & (SD 6.47) \\
\hline Ever & 33,370 & $(57.4)$ & 754 & (75.9) & 205 & (71.4) \\
\hline In the last 12 months & 16,760 & $(28.8)$ & 359 & (36.2) & 128 & $(44.6)$ \\
\hline
\end{tabular}

NOTES: Total sample of GDS 2015 respondents was 89,509. Samples included here include only male respondents. 287 individuals reported recent use of AAS but only 215 individuals completed the survey item assessing motivations so the logistic analyses utilises a sample of 215 . Some percentage totals may not equate to 100 due to missing data 
Table 3. Motivations of AAS use, drinking and night-clubbing behaviour in men reporting AAS use in last 12 months

\begin{tabular}{|c|c|c|}
\hline & \multicolumn{2}{|c|}{$\mathrm{N}=215$} \\
\hline & $\mathrm{N}$ & $(\%)$ \\
\hline \multicolumn{3}{|c|}{ Importance of goals: performance } \\
\hline Not at all important & 31 & $(14.4)$ \\
\hline A bit important & 59 & $(27.4)$ \\
\hline Quite important & 77 & $(35.8)$ \\
\hline Very important & 48 & $(22.3)$ \\
\hline \multicolumn{3}{|l|}{ Importance of goals: weight loss } \\
\hline Not at all important & 74 & $(34.4)$ \\
\hline A bit important & 64 & $(29.8)$ \\
\hline Quite important & 42 & $(19.5)$ \\
\hline Very important & 35 & $(16.3)$ \\
\hline \multicolumn{3}{|l|}{$\begin{array}{l}\text { Importance of goals: building } \\
\text { muscle }\end{array}$} \\
\hline Not at all important & 17 & (7.9) \\
\hline A bit important & 33 & $(15.4)$ \\
\hline Quite important & 68 & $(31.6)$ \\
\hline Very important & 97 & $(45.1)$ \\
\hline \multicolumn{3}{|l|}{ Importance of goals: self esteem } \\
\hline Not at all important & 37 & $(17.2)$ \\
\hline A bit important & 59 & $(27.4)$ \\
\hline Quite important & 65 & $(30.2)$ \\
\hline Very important & 54 & $(25.1)$ \\
\hline \multicolumn{3}{|l|}{ Frequency of heavy drinking } \\
\hline Never & 29 & $(13.5)$ \\
\hline Less than monthly & 96 & $(44.7)$ \\
\hline Monthly & 40 & $(18.6)$ \\
\hline Weekly or more & 50 & $(23.3)$ \\
\hline \multicolumn{3}{|l|}{ Frequency of clubbing } \\
\hline Never & 33 & $(15.4)$ \\
\hline $\begin{array}{l}\text { Less than once every three } \\
\text { months }\end{array}$ & 31 & $(14.4)$ \\
\hline Once every three months & 35 & $(16.3)$ \\
\hline Once a month & 44 & $(20.5)$ \\
\hline Once a fortnight & 31 & $(14.4)$ \\
\hline Weekly or more & 41 & $(19.1)$ \\
\hline
\end{tabular}


Table 4. Logistic regression predicting probability of stimulant use

\begin{tabular}{|c|c|c|c|}
\hline \multirow{3}{*}{ Age } & \multicolumn{3}{|c|}{ Recent use of AAS \& stimulant drugs $(\mathrm{N}=215)$} \\
\hline & $\beta$ & OR & $95 \% \mathrm{CI}$ \\
\hline & 0.02 & 1.02 & $0.98,1.06$ \\
\hline \multicolumn{4}{|l|}{ Region of residence (ref: Europe) } \\
\hline North America & -0.93 & 0.39 & $0.11,1.47$ \\
\hline Oceania & -0.64 & 0.53 & $0.15,1.87$ \\
\hline South Americas & $-0.89 *$ & 0.41 & $0.18,0.96$ \\
\hline Other & 0.52 & 1.68 & $0.10,26.90$ \\
\hline \multicolumn{4}{|l|}{ Employment (ref: employed) } \\
\hline Unemployed/student & 0.53 & 1.71 & $0.75,3.90$ \\
\hline \multicolumn{4}{|l|}{ Education (ref: High school) } \\
\hline Tafe or certificate & -0.80 & 0.45 & $0.17,1.16$ \\
\hline University & -0.28 & 0.76 & $0.28,2.09$ \\
\hline \multicolumn{4}{|l|}{$\begin{array}{l}\text { Importance of goals: performance } \\
\text { (ref: not important) }\end{array}$} \\
\hline A bit important & 0.17 & 1.19 & $0.35,4.05$ \\
\hline Quite important & -0.17 & 0.84 & $0.26,2.69$ \\
\hline Very important & $-1.21^{\wedge}$ & 0.30 & $0.08,1.08$ \\
\hline \multicolumn{4}{|l|}{$\begin{array}{l}\text { Importance of goals: weight loss } \\
\text { (ref: not important) }\end{array}$} \\
\hline A bit important & 0.55 & 1.74 & $0.70,4.30$ \\
\hline Quite important & $1.60 * *$ & 4.94 & $1.66,14.66$ \\
\hline Very important & $1.31 *$ & 3.71 & $1.07,12.85$ \\
\hline \multicolumn{4}{|l|}{$\begin{array}{l}\text { Importance of goals: building muscle } \\
\text { (ref: not important) }\end{array}$} \\
\hline A bit important & 0.21 & 1.24 & $0.25,6.20$ \\
\hline Quite important & 0.59 & 1.81 & $0.39,8.38$ \\
\hline Very important & $1.83^{*}$ & 6.25 & $1.28,30.46$ \\
\hline \multicolumn{4}{|l|}{$\begin{array}{l}\text { Importance of goals: self esteem } \\
\text { (ref: not important) }\end{array}$} \\
\hline A bit important & -0.51 & 0.60 & $0.21,1.77$ \\
\hline Quite important & -0.17 & 0.84 & $0.29,2.43$ \\
\hline Very important & -0.45 & 0.64 & $0.18,2.22$ \\
\hline \multicolumn{4}{|l|}{$\begin{array}{l}\text { Frequency of heavy drinking } \\
\text { (ref: never) }\end{array}$} \\
\hline Less than monthly & 0.66 & 1.94 & $0.68,5.57$ \\
\hline Monthly & 0.99 & 2.69 & $0.77,9.48$ \\
\hline Weekly or more & $2.60 * * *$ & 13.45 & $3.14,57.56$ \\
\hline \multicolumn{4}{|l|}{$\begin{array}{l}\text { Frequency of clubbing } \\
\text { (ref: never) }\end{array}$} \\
\hline Less than once every 3 months & 0.35 & 1.42 & $0.39,5.12$ \\
\hline Once every 3 months & $2.00 * *$ & 7.35 & $1.86,29.06$ \\
\hline Once a month & $1.25^{\wedge}$ & 3.49 & $0.99,12.33$ \\
\hline Once a fortnight & $1.70^{*}$ & 5.47 & $1.27,23.57$ \\
\hline Weekly or more & 0.76 & 2.14 & $0.55,8.32$ \\
\hline \multicolumn{4}{|l|}{ Model information } \\
\hline Constant & -2.30 & 0.10 & $0.01,1.23$ \\
\hline$\chi^{2}$ & & $68.67^{* * *}$ & \\
\hline Pseudo $\mathrm{R}^{2}$ & & 0.24 & \\
\hline Log likelihood & & -106.49 & \\
\hline
\end{tabular}

NOTES: ${ }^{\wedge} 0.10, * \mathrm{p}<0.05, * * \mathrm{p}<0.01,{ }^{* * *} \mathrm{p}<0.001$ 